\title{
1 Lower edge of locked Main Himalayan Thrust unzipped by the 2015
}

\section{Gorkha earthquake}

5

6

7

8

Jean-Philippe Avouac ${ }^{1}$, Lingsen Meng ${ }^{2}$, Shengji Wei ${ }^{3}$, Teng Wang ${ }^{4}$, Jean-Paul Ampuero ${ }^{5}$

${ }^{1}$ Department of Earth Sciences, University of Cambridge, UK

2 Department of Earth, Planetary and Space Sciences, University of California, Los Angeles, CA, USA

${ }^{3}$ Earth Observatory of Singapore, Nanyang Technological University, Singapore

${ }^{4}$ Huffington Department of Earth Sciences, Southern Methodist University, Dallas, TX, USA

${ }^{5}$ Seismological Laboratory, California Institute of Technology, Pasadena, CA, USA

Large earthquakes are thought to release strain on previously locked faults. However, the details of how earthquakes are initiated, grow and terminate in relation to pre-seismically locked and creeping patches is unclear ${ }^{1-4}$. The $2015 \mathrm{Mw} 7.8$ Gorkha, Nepal earthquake occurred close to Kathmandu in a region where the prior pattern of fault locking is well documented ${ }^{5}$. Here we analyze this event using seismological records measured at teleseismic distances and Synthetic Aperture Radar imagery. We show that the earthquake originated northwest of Kathmandu within a cluster of background seismicity that fringes the bottom of the locked portion of the Main Himalayan Thrust fault (MHT). The rupture propagated eastwards for about $140 \mathrm{~km}$, unzipping the lower edge of the locked portion of the fault. High-frequency seismic waves radiated continuously as the slip pulse propagated at about $2.8 \mathrm{~km} \mathrm{~s}-1$ along this zone of presumably high and heterogeneous pre-seismic stress at the seismicaseismic transition. Eastward unzipping of the fault resumed during the Mw 7.3 aftershock on May 12. The transfer of stress to neighbouring regions during the Gorkha earthquake should facilitate future rupture of the areas of the MHT adjacent and up-dip of the Gorkha earthquake rupture.

On April 25 2015, a destructive Mw 7.8 earthquake occurred along the Himalayan front close to Kathmandu (Figure 1). The epicenter was located $80 \mathrm{~km}$ to the west-northwest of Kathmandu 
within a long-identified zone of clustered seismicity which runs beneath the front of the high Himalaya ${ }^{6}$. The focal mechanism ${ }^{7}$ indicating thrusting on a subhorizontal fault dipping about $10^{\circ}$ and the $15 \mathrm{~km}$ hypocentral depth${ }^{7}$ make it likely that this earthquake ruptured the MHT, the main fault along which northern India underthrusts the Himalaya at a rate of approximately 2 $\mathrm{cm} / \mathrm{yr}^{8}$. A Mw7.3 aftershock with a very similar focal mechanism ${ }^{7}$ occurred on May $12,75 \mathrm{~km}$ east of Kathmandu (Figure 1). The geometry of the MHT in the hypocentral area is relatively well known from various geophysical experiments ${ }^{9,10}$. Geodetic measurements collected over the last 20 years revealed that this fault remained locked over this time period ${ }^{5,11}$ and the pattern of locking is now well constrained ${ }^{5}$ (Figure 1), allowing for a detailed comparison with the rupture process during the Gorkha earthquake.

We imaged the rupture process by back-projecting ${ }^{12}$ teleseismic $P$ waves recorded by the Australian seismic network (Figures $2 \mathrm{a}$ and $\mathrm{S} 1$ ) using the Multitaper-MUSIC array processing technique. The technique tracks the spatio-temporal evolution of the sources of high frequency radiation $(0.5-2 \mathrm{~Hz})$ during the rupture process (Figure S2; see Methods). The back-projection forms coherent sources for about 60 s after initiation of the rupture. The high frequency sources are almost linearly distributed for about $45 \mathrm{~s}$ and their timing indicates a $2.72+/-0.13 \mathrm{~km} / \mathrm{s}$ eastward propagation (Figure $2 \mathrm{~b}$ ). They follow remarkably well the downdip edge of the locked zone (Figure 1) and the cluster of background seismicity (Figure 2a) including a local kink northwest of Kathmandu. The amplitude rises sharply from 10 to 20 s, peaks from 20 to 40 s and decays abruptly after about 45 s (Figure $2 c$ ). High frequency radiation persists after 45 s but migrates updip in a southeastward direction. The May 12 aftershock occurred a few tens of 
47 kilometers east of where the initial phase of along strike propagation of the rupture stopped 48 (Figure 2a).

49 We also determined a finite source model of the rupture from the joint inversion ${ }^{13}$ of

50 teleseismic waveforms in the $0.01-1 \mathrm{~Hz}$ frequency band and static surface displacements

51 measured from SAR image offsets. The fault is assumed planar and its dip angle was adjusted to

$527^{\circ}$ by trial and. The model assumes that, once initiated, slip accrues over a certain duration (rise

53 time) in the wake of the rupture front. The inversion solves for the final slip amplitude, rake,

54 rise-time and rupture front velocity at each grid point (see Methods). The source model is

55 determined so as to best fit the static surface displacements (Figure S3) and teleseismic

56 waveforms (Figure S4). The static surface displacements were measured using European Space

57 Agency's Sentinel-1 radar images acquired on $17^{\text {th }}$ and $29^{\text {th }}$ of April, and $9^{\text {th }}$ April and $3^{\text {rd }}$ May.

58 We ignored the possibility of postseismic deformation over the 4 and 8 days following the event

59 (see Methods). The finite-source model (Figure 2) shows that the rupture propagated eastward

60

61

62

63

64

65

66

67 at $3.0+/-0.5 \mathrm{~km} / \mathrm{s}$ on average (Figure S5). The slip area is about $120 \mathrm{~km}$ in length along strike and $50 \mathrm{~km}$ in width along dip. The implied moment tensor is nearly identical to the $\mathrm{W}$-phase moment tensor (Figure 1). Altogether the earthquake released a total moment of $7.2 \times 10^{20}$ N.m, corresponding to a moment magnitude $\mathrm{Mw}$ 7.84. The moment rate function shows a simple rupture with a single major pulse of 50s duration (Figure 2c). The May 12 aftershocks falls in a gap of relatively low slip at the eastward termination of the mainshock.

The results from the back-projection and finite source inversion are in remarkable agreement during the first $45 \mathrm{~s}$ of the rupture. The moment release rate and the power of the high 
68 frequency sources show the same temporal pattern (Figure 2c). Both source imaging techniques reveal a unilateral pulse-like rupture with a narrow strip of active slip, $20-30 \mathrm{~km}$ wide along strike, propagating eastwards at about 2.7 to $3.0 \mathrm{~km} / \mathrm{s}$ (Figure 3 and Supplementary

71 Animation). Contrary to the backprojection, the finite source model yields a rupture velocity

72 which is sensitive to the epicentral location, which can be off by more than $10 \mathrm{~km}$. Given the

73 various possible sources of errors, we estimate that the two analysis agree within uncertainties

74 and indicate a rupture velocity of $2.8+/-0.3 \mathrm{~km} / \mathrm{s}$.

75 Because the finite-source inversion assumes a rupture front expanding from the epicenter and

76 because the teleseismic waveforms only constrain robustly the moment rate function, the slip

77 distribution for each time interval is smeared along the quasi-circular isochrons of the rupture

78 front (Figure 3). The SAR data help limit this smearing effect by forcing the cumulative slip

79 distribution to match the west-east trending narrow zone of surface deformation along the 80 rupture-propagation pathway (Figure S3). The northern edge of the high slip area correlates

81 with the location of the high frequency sources and with the edge of the locked zone (Figure

82 2a). After $45 \mathrm{~s}$ the source model is less well constrained because of the lower signal-to-noise

83 ratio and the pulse becomes more diffuse and smeared along isochrons.

84

85

86

87 88
Both the back-projection results and the finite-fault source model suggest that the earthquake unzipped the downdip edge of the locked zone, propagating mostly as a mode-III crack. The persistent radiation of high frequency waves along the whole rupture length is probably due to the high and heterogeneous stresses built up at the transition between the locked and the creeping zone. The stress heterogeneities can result from intermingling of creeping and locked 
areas at a scale not resolvable with surface geodesy. Another factor contributing to stress heterogeneity is the background seismicity, which is well understood to be triggered by stress build-up at the downdip edge of the locked zone $e^{5,14}$. The correlation between the moment rate and the power of high frequency seismic radiations suggests that the high frequency sources are "riding the wave" of an ongoing slip pulse. It is interesting to note that, although tremorsand-slip events are note directly comparable to standard earthquakes, a similar correlation has been observed during tectonic tremor episodes on subduction megathrust ${ }^{15}$. The Gorkha earthquake actually shares similarities with earthquakes observed near the downdip end of the

97 locked subduction megathrust ${ }^{1}$ (zone $\mathrm{C}$ of Lay et al. $^{16}$ ). In both settings, the high frequency sources are found to radiate from the lower edge of the locked fault zone.

The rupture during the Gorkha earthquake expanded upwards from the locked edge, but not much downwards probably because the zone of aseismic slip acted as an efficient barrier ${ }^{4}$ to

101 downdip propagation of the seismic rupture or because of the restraining effect of a ramp 102 along the $\mathrm{MHT}^{6}$. The pattern of coupling can thus explain the location of the earthquake 103 initiation and the rupture process but not its arrest along strike.

104 The rupture seems to have derailed from its linear along-strike propagation after $\sim 45$ s close to 105 the location of the May $12 \mathrm{Mw} 7.3$ aftershock, although the trend toward the Australian network suggest that it could reflect a 'swimming' artifact (mitigation of this artifact by the 107 MUSIC technique is imperfect when the energy gets weak). In any case, the eastward rupture propagation was possibly arrested when it encountered some structural complexity, a zone of 
110 inhibited the rupture propagation. Interestingly, the mainshock and the May 12 aftershock

111 ruptured nearly entirely a segment of persistently intense background seismicity over the last

11220 years of local seismic monitoring. The rupture initiated clearly at the western end of this

113 segment. Lateral variations of the background seismicity and of the pattern and intensity of

114 high frequency sources could reflect lateral ramps along the $\mathrm{MHT}^{17}$.

115 The 2015 Gorkha earthquake is similar in location to the 1833 earthquake, with estimated

116 magnitude Mw 7.6-7.7, which also caused heavy damages in Kathmandu ${ }^{18,19}$. These

117 earthquakes clearly did not propagate to the front of the Himalaya where the MHT emerges at

118 the surface. Paleoseismological studies have shown that several larger Himalayan earthquakes

119 did however reach the surface ${ }^{20,21}$. In particular, the 1934 Bihar-Nepal earthquake ${ }^{22}$ ruptured

120 the MHT east of Kathmandu (Figure 1) producing over $6 \mathrm{~m}$ of slip at the surface and reaching an

121 estimated magnitude of $\mathrm{Mw} 8.2^{23}$. Its rupture extent is weakly constrained but consistent with

122 the possibility that the Gorkha earthquake sequence arrested because of the lower stress level

123 left by the 1934 event or due to some local complexity of structural origin. A lateral ramp of the

$124 \mathrm{MHT}$, or an heterogeneity of fault friction, for example a small patch with rate-strengthening

125 friction not resolvable with the interseismic geodetic data, could have resulted in a barrier

126 effect and a persistent segmentation of the MHT.

127 A previous large earthquake in 1255 also reached the surface 22,23 . The area east of Kathmandu

128 seems unlikely to rupture again in the near future in a large (say Mw>7.5) event. The 81 yr time

129 span since 1934 is short in comparison to the 679 yr separation between 1255 and 1934; the

130 acumulated slip deficit since 1934 amounts to less than $2 \mathrm{~m}$. The 1813 and 2015 earthquakes 
131 must have contributed to the process of upward transfer of the stresses which build up around

132 the downdip edge of the locked fault zone in the interseismic period. This mechanism is

133 observed in dynamic models of the seismic cyle and ultimately leads to rupture of the whole

134 locked zone ${ }^{24}$. It is also possible that the 2015 and 1833 earthquakes produced similar ruptures

135 and failed to rupture the locked portions of the MHT beneath and west of the Kathmandu basin

136 because of some persistent barrier of mechanical or structural origin. Yet another possibility is

137 that slip on the updip locked portion of the MHT is not entirely seismic. The stress increase

138 could in principle be released by afterslip if the updip fault portion obeyed a rate-strengthening

139 friction law and were previously lying in the stress shadow ${ }^{25}$ of the asperity which ruptured in

140 2015. If so, it should be observed to slip aseismically in the postseismic period.

141 The locked portion of the MHT west of the 2015 event calls for special attention as the nearly

$142800 \mathrm{~km}$ long stretch between the 1833/2015 ruptures and the $1905 \mathrm{Mw} 7.8$ Kangra earthquake

143 is a well identified seismic gap with no large earthquake for over 500 years ${ }^{17,21,26}$. The MHT is

144 clearly locked there (Figure 1) and its deficit of slip could exceed $10 \mathrm{~m}$. The last large

145 earthquake there occurred in 1505, and could have exceeded Mw $8.5^{27}$. This event produced

146 significant damage in southern Tibet and ruptured the Himalayan foothills at the surface ${ }^{28}$.

147 While the size of that particular event is debated, there is general consensus that major

148 earthquakes ( $\mathrm{Mw}>8.5$ ) occurred along that stretch of the Himalaya, and could have produced

149 over $10 \mathrm{~m}$ of slip along the Himalayan front ${ }^{17,21,26}$. 


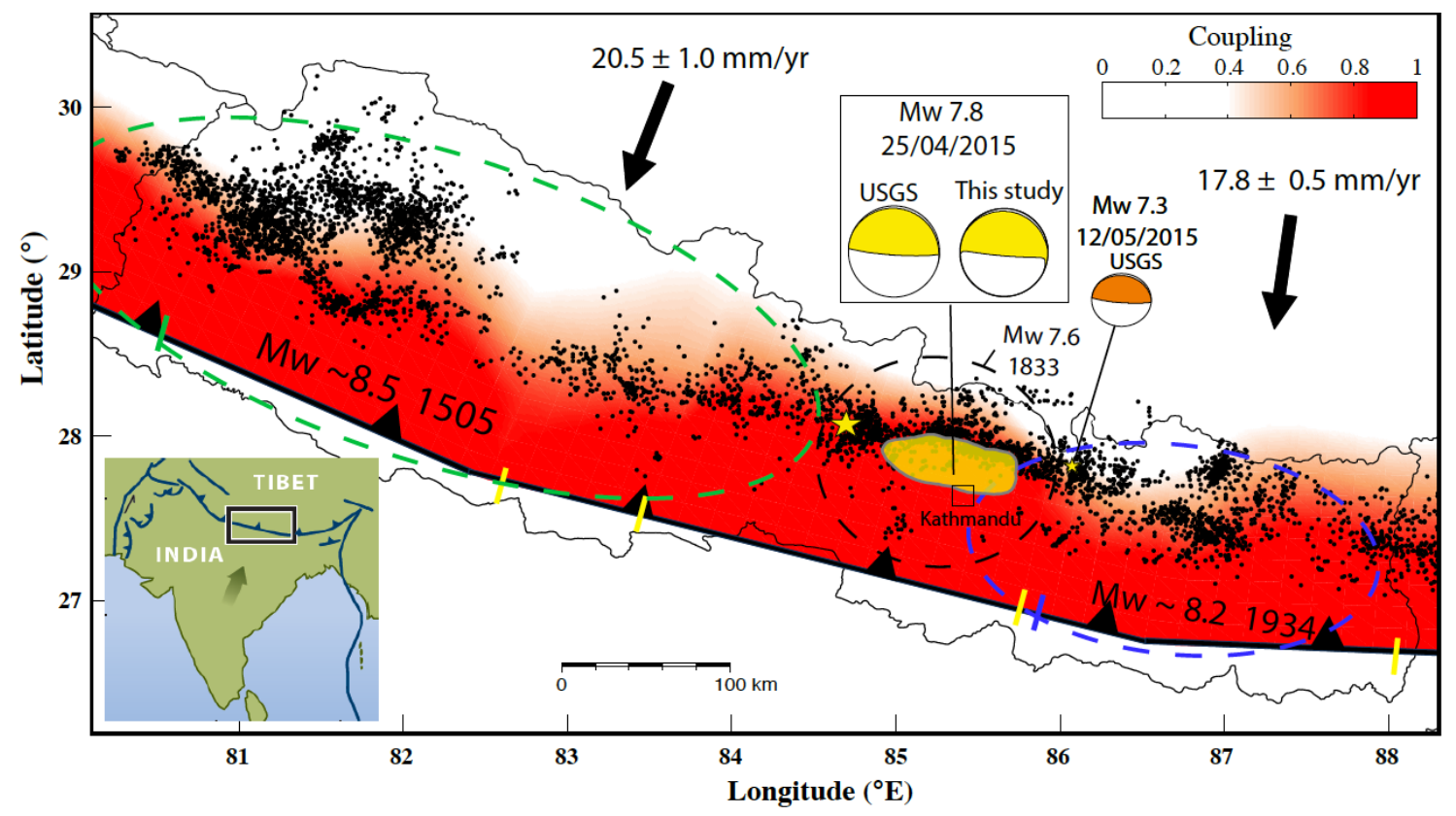

151 Figure 1: Seismotectonic context of the 2015 Mw 7.8 Gorkha earthquake. Yellow patch shows

152 area with $>1 \mathrm{~m}$ coseismic slip. Epicenter (star), centroid location and W-phase moment tensor

153 from USGS $^{7}$. Interseismic coupling and convergence rate across the Himalaya from Ader et al. ${ }^{5}$.

154 Dots show 1995-2003 relocated seismicity ${ }^{29}$. Mw>7.5 historical events since $1505^{17-19,22}$ are

155 estimated to have occurred within the ellipses. Blue and green short lines show locations of

156 documented surface rupture in 1934 and 1505 respectively ${ }^{23,28}$. Yellow short lines indicate

157 surface ruptures more probably related to older events (possibly in $1255 \mathrm{AD})^{17,23}$. Inset: map

158 location and motion of India relative to Eurasia. 
(a)
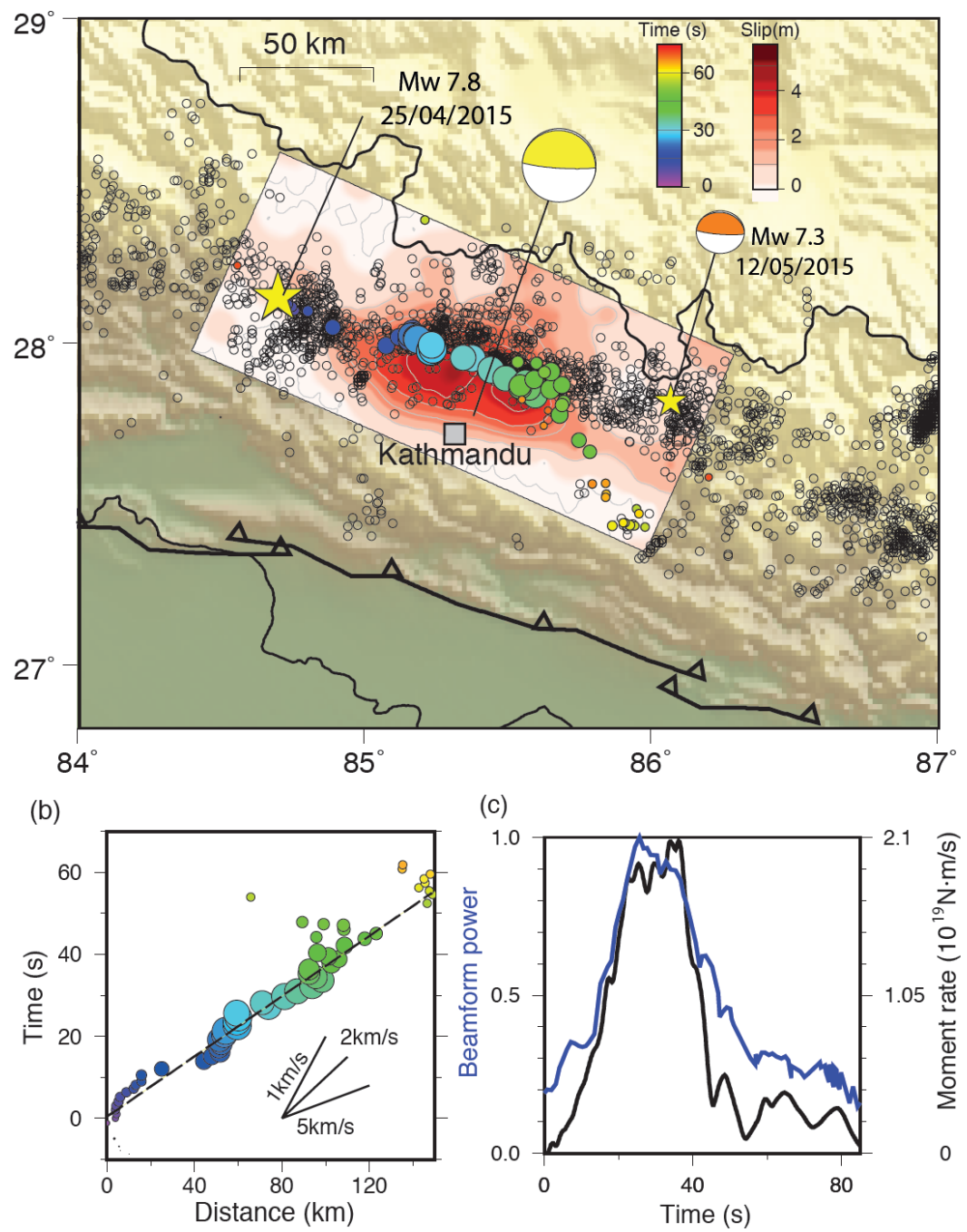

(c)

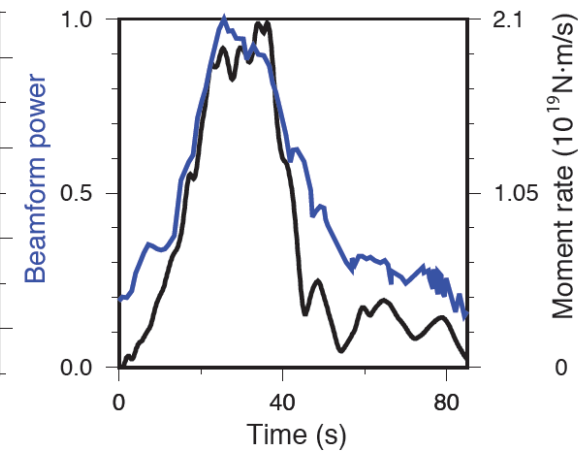

160 Figure 2: Seismic rupture kinematics. (a) Co-seismic slip determined from joint inversion of

161 teleseismic waveforms and SAR measurements (red shading) and locations of high frequency

$162(0.5-2 \mathrm{~Hz})$ sources determined from backprojection of teleseismic waves (dots). Size is

163 proportional to beamforming amplitude and color indicates time of each window center

164 relative to hypocentral time. Open circles show relocated background 1995-2003 seismicity ${ }^{29}$.

165 (b) Timing of high frequency sources as a function of distance along strike. Least squares linear regression (dashed line) indicates a rupture speed of $2.72+/-0.13 \mathrm{~km} / \mathrm{s}$. (c) Relative

167 beamforming power (blue) and moment release rate from finite source inversion (black). 

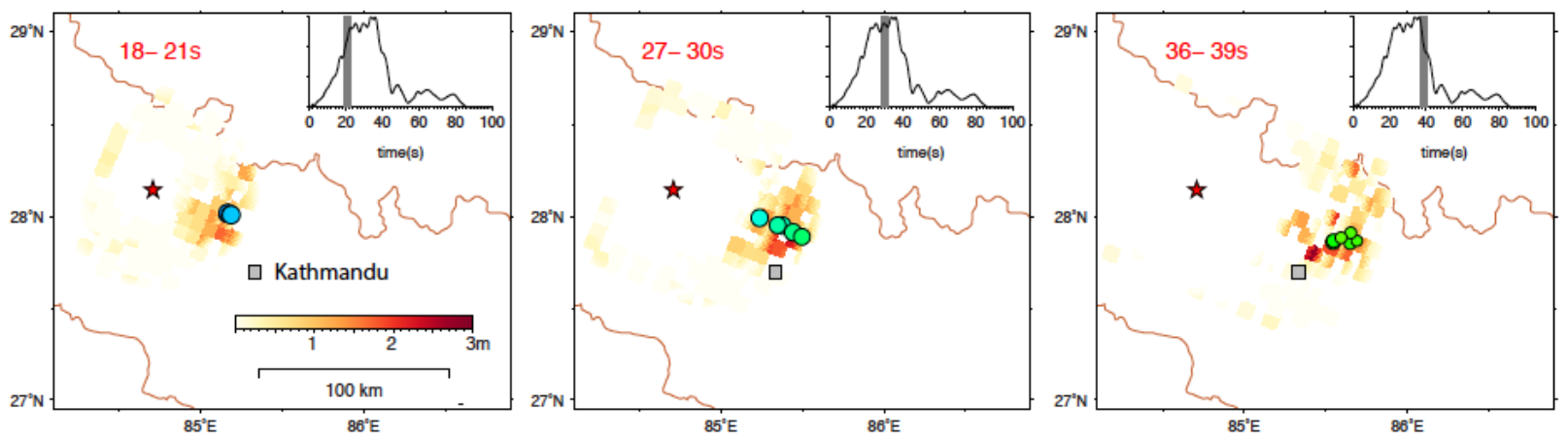

171 Figure 3: Time snapshots of seismic rupture evolution. Each plot shows slip (background

172 colors) and high-frequency sources (dots, colored by their rupture time, same scale as in Figure 2)

173 occurring within a 3s window indicated by a grey band over the source time function in the

174 inset. An animation is provided as supplementary material. 
1771 Schurr, B. et al. Gradual unlocking of plate boundary controlled initiation of the 2014 Iquique earthquake. Nature 512, 299-302, doi:10.1038/nature13681 (2014).

1792 Loveless, J. P. \& Meade, B. J. Spatial correlation of interseismic coupling and coseismic rupture extent of the $2011 \mathrm{M}-\mathrm{W}=9.0$ Tohoku-oki earthquake. Geophysical Research Letters 38, doi:10.1029/2011gl048561 (2011).

1823 Yue, H. et al. The 5 September 2012 Nicoya, Costa Rica M-w 7.6 earthquake rupture process from joint inversion of high-rate GPS, strong-motion, and teleseismic $\mathrm{P}$ wave data and its relationship to adjacent plate boundary interface properties. Journal of Geophysical Research-Solid Earth 118, 5453-5466, doi:10.1002/jgrb.50379 (2013).

1864 Kaneko, Y., Avouac, J. P. \& Lapusta, N. Towards inferring earthquake patterns from geodetic observations of interseismic coupling. Nature Geoscience 3, 363-U324, doi:10.1038/ngeo843 (2010).

5 Ader, T. et al. Convergence rate across the Nepal Himalaya and interseismic coupling on the Main Himalayan Thrust: Implications for seismic hazard. Journal of Geophysical Research-Solid Earth 117, doi:10.1029/2011jb009071 (2012).

1926 Pandey, M. R., Tandukar, R. P., Avouac, J. P., Lave, J. \& Massot, J. P. Interseismic Strain Accumulation on the Himalaya Crustal Ramp (Nepal). Geophysical Research Letters 22, 751-754 (1995).

1957 USGS. The 2015 Gorkha earthquake http://earthquake.usgs.gov/earthquakes/eventpage/us20002926 and its Mw 7.3 aftershock http://earthquake.usgs.gov/earthquakes/eventpage/us20002ejl - general_summary, 2015). 
1988 Lavé, J. \& Avouac, J. P. Active folding of fluvial terraces across the Siwaliks Hills, Himalayas of central Nepal. Journal of Geophysical Research-Solid Earth 105, 5735-5770 (2000).

9 Nabelek, J. et al. Underplating in the Himalaya-Tibet Collision Zone Revealed by the HiCLIMB Experiment. Science 325, 1371-1374, doi:10.1126/science.1167719 (2009).

10 Lemonnier, C. et al. Electrical structure of the Himalaya of Central Nepal: high conductivity around the mid-crustal ramp along the MHT. Geophysical Research Letters 26, 3261-3264 (1999).

11 Bilham, R. et al. GPS measurements of present-day convergence across the Nepal Himalaya. Nature 386, 61-64 (1997).

12 Ishii, M., Shearer, P. M., Houston, H. \& Vidale, J. E. Extent, duration and speed of the 2004 Sumatra-Andaman earthquake imaged by the Hi-Net array. Nature 435, 933-936 (2005).

Ji, C., Wald, D. \& Helmberger, D. V. Source Description of the 1999 Hector Mine, California Earthquake, Part I: Wavelet Domain Inversion Theory and Resolution Analysis. Bulletin of the Seismological Society of America 92, 1192-1207 (2002).

14 Cattin, R. \& Avouac, J. P. Modeling mountain building and the seismic cycle in the (2000). seismically and geodetically detected slow earthquakes. Geophysical Research Letters 35, doi:10.1029/2008gl034014 (2008). 
22016 Lay, T. et al. Depth-varying rupture properties of subduction zone megathrust faults.

$221 \quad$ Journal of Geophysical Research-Solid Earth 117, doi:10.1029/2011jb009133 (2012).

22217 Mugnier, J. L. et al. Structural interpretation of the great earthquakes of the last millennium in the central Himalaya. Earth-Science Reviews 127, 30-47, doi:10.1016/j.earscirev.2013.09.003 (2013).

22518 Ambraseys, N. N. \& Douglas, J. Magnitude calibration of north Indian earthquakes. Geophysical Journal International 159, 165-206 (2004).

22719 Bilham, R. Location and Magnitude of the 1833 Nepal Earthquake and Its Relation to the 228 Rupture Zones of Contiguous Great Himalayan Earthquakes. Current Science 69, 101-128 (1995).

23020 Lavé, J. et al. Evidence for a great medieval earthquake (approximate to 1100 AD) in the $231 \quad$ Central Himalayas, Nepal. Science 307, 1302-1305 (2005).

23221 Kumar, S. et al. Paleoseismic evidence of great surface-rupture earthquakes along the Indian Himalaya. Journal of Geophysical Research-Solid Earth 111, doi: 10.1029/2004JB003309 (2006).

23522 Sapkota, S. N. et al. Primary surface ruptures of the great Himalayan earthquakes in 236 1934 and 1255. Nature Geoscience 6, 71-76, doi:10.1038/ngeo1669 (2013).

23723 Bollinger, L. et al. Estimating the return times of great Himalayan earthquakes in eastern Nepal: Evidence from the Patu and Bardibas strands of the Main Frontal Thrust. Journal of Geophysical Research-Solid Earth 119, 7123-7163, doi:10.1002/2014jb010970 (2014).

24024 Lapusta, N., Rice, J. R., Ben-Zion, Y. \& Zheng, G. T. Elastodynamic analysis for slow tectonic loading with spontaneous rupture episodes on faults with rate- and state- 
dependent friction. Journal of Geophysical Research-Solid Earth 105, 23765-23789 (2000).

24425 Burgmann, R. et al. Interseismic coupling and asperity distribution along the Kamchatka 245 subduction zone. Journal of Geophysical Research-Solid Earth 110 (2005).

24626 Rajendran, C. P., John, B. \& Rajendran, K. Medieval pulse of great earthquakes in the

27 Bilham, R. \& Wallace, K. Future $M w>8$ earthquakes in the Himalaya: implications from the 26 Dec 2004 Mw=9.0 earthquake on India's eastern plate margin. Geol. Surv. India Spl. Pub 85, 1-14 (2005).

25228 Yule, D., S. Dawson, J. Lave, S. Sapkota, and D. Tiwari. in AGU Fall Meeting.

25329 Rajaure, S., S. N. Sapkota, L. B. Adhikari, B. Koirala, M. Bhattarai, D. R. Tiwari, U. Gautam, 254

25730 Vandecar, J. C. \& Crosson, R. S. Determination of teleseismic relative phase arrival times 258

31 Meng, L. S., Inbal, A. \& Ampuero, J. P. A window into the complexity of the dynamic rupture of the 2011 Mw 9 Tohoku-Oki earthquake. Geophysical Research Letters 38, doi:10.1029/2011gl048118 (2011). 
26332 Meng, L., Ampuero, J. P., Sladen, A. \& Rendon, H. High-resolution backprojection at regional distance: Application to the Haiti M7.0 earthquake and comparisons with finite source studies. Journal of Geophysical Research-Solid Earth 117, doi:10.1029/2011jb008702 (2012).

26733 Meng, L. S., Ampuero, J. P., Luo, Y. D., Wu, W. B. \& Ni, S. D. Mitigating artifacts in backprojection source imaging with implications for frequency-dependent properties of the Tohoku-Oki earthquake. Earth Planets and Space 64, 1101-1109,

27134 De Zan, F. \& Guarnieri, A. M. TOPSAR: Terrain observation by progressive scans. IEEE Transactions on Geoscience and Remote Sensing 44, 2352-2360, doi:10.1109/tgrs.2006.873853 (2006).

274

35 Wegmuller, U., Werner, C. \& ESA. in Third Ers Symposium on Space at the Service of Our 275 Environment, Vols. Ii \& lii Vol. 414 ESA Special Publications 1687-1692 (1997).

27636 Michel, R., Avouac, J. P. \& Taboury, J. Measuring ground displacements from SAR amplitude images: application to the Landers earthquake. Geophysical Research Letters 26, 875-878 (1999).

37 Wang, T., Jonsson, S. \& Hanssen, R. F. Improved SAR Image Coregistration Using PixelOffset Series. IEEE Geoscience and Remote Sensing Letters 11, 1465-1469, doi:10.1109/Igrs.2013.2295429 (2014).

38 Jonsson, S., Zebker, H., Segall, P. \& Amelung, F. Fault slip distribution of the 1999 M-w 7.1 Hector Mine, California, earthquake, estimated from satellite radar and GPS measurements. Bulletin Of The Seismological Society Of America 92, 1377-1389 (2002). 
39 Bamler, R. \& Eineder, M. Accuracy of differential shift estimation by correlation and split-bandwidth interferometry for wideband and Delta-k SAR systems. IEEE Geoscience and Remote Sensing Letters 2, 151-155, doi:10.1109//grs.2004.843203 (2005).

40 Tinti, E., Bizzarri, A. \& Cocco, M. Modeling the dynamic rupture propagation on heterogeneous faults with rate- and state-dependent friction. Annals of Geophysics 48, 327-345 (2005).

41 Mahesh, P. et al. One-Dimensional Reference Velocity Model and Precise Locations of Earthquake Hypocenters in the Kumaon-Garhwal Himalaya. B Seismol Soc Am 103, 328339 (2013).

Correspondence and requests for materials should be addressed to Jean-Philippe Avouac (avouac@gps.caltech.edu)

Acknowledgements: Sentinel-1A data are provided by the European Space Agency. TW thank J. Kim from SMU for helps in processing the SAR data. We thank three anonymous reviewers for their constructive comments and thoughtful suggestions, as well as the editor Amy Whitchurch. We also thank Roland Burgmann for comments on an earlier version of this study,

Authors contribution: JPhA coordinated the research and wrote the article. LM and JPA carried out the backprojection. SW carried out the finite-source modeling. TW carried out the SAR offset measurements. All authors contributed to the interpretation and writing of the article.

The authors declare no competing financial interests. 
We describe here the methods used in this study. The corresponding codes are not available online as these are not user-friendly codes with manuals, but they can be provided upon requests sent to the authors. The waveform data are available from the Incorporated Research Institutions for Seismology web site (http://www.iris.edu/hq/).

\section{Back projection of high frequency teleseismic seismic waveforms}

The coseismic rupture process of $2015 \mathrm{Mw} 7.8$ Gorkha earthquake is well imaged by the backprojection (BP) approach, which provides a high frequency view of the rupture process. In contrast to classic source inversions based on waveform fitting, the approach does not require the detailed knowledge of the Green's function and relies solely on the timing information of coherent seismograms. The BP approach is therefore less affected by the uncertainty of seismic velocity structures or the assumptions of fault geometry and rupture kinematics. The BP analysis is typically performed on coherent seismograms recorded at teleseismic distances. Here, we use the seismograms recorded by the Australian seismic network (AU), composed of 54 broadband stations evenly distributed across the continental Australia with epicentral distances between $60^{\circ}$ and $95^{\circ}$ (Fig. S1). The data of the AU network are available from the IRIS data center (http://www.iris.edu). We band pass the AU seismograms between $2 \mathrm{~s}$ and $0.5 \mathrm{~s}$, the highest band with relatively high waveform coherency (Fig. S2). We aligned the initial P-wave arrivals of the filtered waveforms with a multi-channel cross-correlation technique ${ }^{30}$. The first arrival is assumed to come from the USGS hypocenter location $\left(84.71^{\circ} \mathrm{E}, 28.15^{\circ} \mathrm{N}\right)$. The location of the later HF sources are determined based on the differential travel time relative to the hypocenter. Since differential travel time is not sensitive to relatively small source depth changes along the shallow dipping MHT, we back-projected the waveforms onto a horizontal fault plane at a depth of $15 \mathrm{~km}$ based on the IASP91 velocity model. We adopted the Multitaper-MUSIC array processing technique ${ }^{31}$ which resolves more closely spaced sources and are less sensitive to aliasing, yielding a sharper image of the rupture process than the standard beamforming $\operatorname{approach}^{32}$. We also applied a "reference window" strategy ${ }^{33}$, which eliminates the "swimming" artifacts, a systematic apparent drift of the HF energy towards the station arrays. 


\section{SAR Data and processing}

336 We used two pairs (descending Path 19 and ascending Path 85) of Sentinel-1A Synthetic Aperture Radar (SAR) images from the European Space Agency to map the surface deformation caused by the earthquake. The radar images were acquired in the Terrain Observation by Progressive Scan (TOPS) mode, which is designed for carrying out routine, SAR-based observations $^{34}$. We aligned the post-seismic image (acquired on April $29^{\text {th }}$ and May $3^{\text {rd }}$ ) along with the pre-seismic image (acquired on April $17^{\text {th }}$ and $9^{\text {th }}$ ) by using the GAMMA software ${ }^{35}$, and then calculated cross-correlation between uniformly distributed non-overlapping 64-by-64 sub-images on the co-registered radar amplitude images. The peak location in the obtained crosscorrelation surface indicates the offset between the two sub-images in azimuth (satellite traveling direction) and in range (radar line-of-sight direction, LOS) $)^{36,37}$.

Offsets between the SAR image pair are attributed to the ground displacement as well as to imaging geometry differences and topography. We therefore calculated the geometric offsets from the orbital information and the Shuttle Radar Topography Mission Digital Elevation Model $(\text { SRTM DEM) })^{37}$. After the geometric correction, a low-frequency trend still exists in the offsets field, probably due to the inaccurate orbital information. We removed this component by fitting a polynomial surface from the offsets located in the far field. We used an initial slip model to generate two synthetic surface displacements in the radar LOS and azimuth directions. The derived range offsets measure ground displacement in the radar LOS directions that are from 32 to 46 degrees from the vertical with a component towards the west and east, while the azimuth offsets measures along-track components, which is in about SSW (191 ${ }^{\circ}$ eastward from North) and NNW ( $11^{\circ}$ westward from North) for the descending and ascending data, respectively. For each downsampled data point, we calculated the line-of-sight vector based on its geo-location and the satellite orbital information. We used the predicted displacements to generate two quadtree sub-sampling grids ${ }^{38}$, on which we extracted median values from offsets within each grid, resulting in 263 and 715 data points in azimuth and range from the descending track P19, and 499 and 786 data points from the ascending track P85, in azimuth and range, respectively (Figure S3). 
The accuracy of SAR image offsets depends on the cross-correlation peak and can reach around $1 / 10-1 / 20$ of the pixel spacing ${ }^{39}$. For the Sentinel-1A TOPS image, the azimuth and range pixel spacing are $14 \mathrm{~m}$ and $2.3 \mathrm{~m}$ respectively, as a consequence, azimuth offsets are only useful when the north-south component of the horizontal deformation is large, which is the case for the Gorkha earthquake. Range offsets measure the surface deformation in the same direction as interferometry, which can be formed from the same SAR image pair. However the phase information is seriously decorrelated in the Himalaya mountainous areas. In addition, the high deformation gradient surrounding the peak deforming area may result in aliasing phase values. Both factors can cause un-reliable phase unwrapping results, we therefore decide to use image offsets data for our model inversion.

\section{Finite source modeling and inversion procedure}

We downloaded GSN broadband data from the IRIS DMC. We analyzed 40 teleseismic P and 37 SH waveforms selected based upon data quality and azimuthal distribution. Waveforms are first converted to displacement by removing the instrument response at the frequency range lower than $1 \mathrm{~Hz}$. The geodetic data were obtained by cross-correlation of sentinel-1 SAR data, both for ascending and descending images (see previous section for more details).

We approximate the fault geometry with a planar fault segment with strike of $293^{\circ}$ and dip of $7^{\circ}$ (GCMT), each discretized in $8 \times 8 \mathrm{~km}^{2}$ subfaults. The model assumes that the rupture consists of propagating rupture front with slip accruing in the wake of the passage of the rupture front. The slip history at each grid point $(\mathrm{j}, \mathrm{k})$ on the fault is represented by $D \times \dot{S}_{j k}(t)$, where $\dot{S}_{j k}(t)$ is the slip-rate function which specifies how a point on the fault slips in time, and $D$ is the cumulative (or 'static') slip. The rise-time function is represented by a cosine function parameterized by the duration of slip, the so-called rise-time. Because the seismograms are bandpass-filtered, this rather smooth slip-rate function is adapted although a more abrupt slip-rate function would probably be more realistic ${ }^{40}$. For each subfault, we solve for the slip amplitude and rake, rise time and rupture velocity. The Green's functions are generated assuming a 1-D model derived a local seismic network ${ }^{41}$ (Table S1). 
The determination of a finite fault slip model is an underdetermined problem due to the large number of unknowns and numerous trade-off among model parameters, such as rise time and rupture velocity. In the present case the trade-offs are significantly reduced if coseismic geodetic observations are available and inverted jointly with the seismological data. Even so, the determination of a finite fault source remains generally underdetermined if the fault discretization is too fine. One way to regularize the inversion is setting some constraints on the roughness of the slip distribution which is the approach adopted here.

We define the best fit model as having the lowest objective function, given as:

Misfit $=E w f+W I * E I+W S * S+W w^{*} M$,

where $E w f$ is the waveform misfit, $E I$ is the geodetic misfit, $S$ is a normalized, second derivative of slip between adjacent patches (a so-called Laplacian smoothing). $M$ is a normalized seismic moment, and $W I, W S$ and $W w$ are the relative weighting applied to the geodic misfit, smoothing, and moment, respectively. The least squares misfits are calculated for the teleseismic and geodetic data. Here we test different values of $W I$, and we found that by setting the weight for the geodetic misfits twice as large as for the waveform misfits did not significantly degrade the fits to the teleseismic or geodetic data between the individual and joint inversions given the normalizations schemes. The static Green's functions at free surface are calculated by using the same 1D velocity model (Table S1) as used in teleseismic body-wave calculation. The fit to the $\mathrm{P}$-waves is given twice as much weight as that to the $\mathrm{SH}$-waves. There are mainly two reasons for this: 1. It is much easier to pick P-wave first arrivals than SH-wave, due to larger noise in the SH-waves; 2. The SH-waves are usually more sensitive to the 3D velocity structure. Thus in general, the SH-wave fits are not as good as P-waves, in particular for thrust events. Here the Pwaves and geodetic data are the most robust and clean data and thus provide the better constrains on the rupture process.

We use a simulated annealing algorithm ${ }^{13}$ to find the best fitting model parameters for the joint inversions for coseismic slip. This nonlinear, iterative inversion algorithm is designed to avoid 
420 local minima by searching broadly through parameter space in initial steps, and then in later 421 iterations to focus on regions that fit the data well.

422 We determined the best-fitting mean rupture velocity by imposing the rupture velocity to be 423 constant. Figure S5 shows how the fit to waveforms varies for rupture velocities between 1 and $4244 \mathrm{~km} / \mathrm{s}$. The best fitting value is $3.0+/-0.5 \mathrm{~km} / \mathrm{s}$. We next performed an inversion with variable 425 rupture velocity (Figure S6).

426 


\section{Supplements to 'Lower edge of locked Main Himalayan Thrust unzipped by the 2015 Gorkha earthquake'}

432 Supplementary animation : 'GorkhaEQ-kimematics.gif' shows the time evolution of the 433 seismic rupture during the Mw 7.8 Gorkha earthquake of April 25, 2015 derived from our 434 seismological study. Each frame shows slip (background color shading) occurring within a $3 \mathrm{~s}$ 435 window indicated by a grey band over the source time function in the inset. The high-frequency 436 sources imaged by back-projection up to the snapshot time (dots, colored by their rupture time) 437 are also plotted up to the frame time. 
439 Table S1: 1D velocity model in the source region.

\begin{tabular}{llll}
\hline $\mathbf{V p}(\mathbf{k m} / \mathbf{s})$ & $\mathbf{V s}(\mathbf{k m} / \mathbf{s})$ & Density $\left(\mathbf{g} / \mathbf{c m}^{3}\right)$ & Thickness $(\mathbf{k m})$ \\
\hline 5.50 & 3.20 & 2.53 & 4.0 \\
5.85 & 3.40 & 2.64 & 12.0 \\
6.00 & 3.50 & 2.69 & 4.00 \\
6.45 & 3.70 & 2.83 & 6.50 \\
6.65 & 3.85 & 2.90 & 10.00 \\
7.20 & 4.15 & 3.07 & 5.00 \\
7.50 & 4.20 & 3.17 & 14.00 \\
7.90 & 4.30 & 3.30 & 15.00 \\
\hline
\end{tabular}

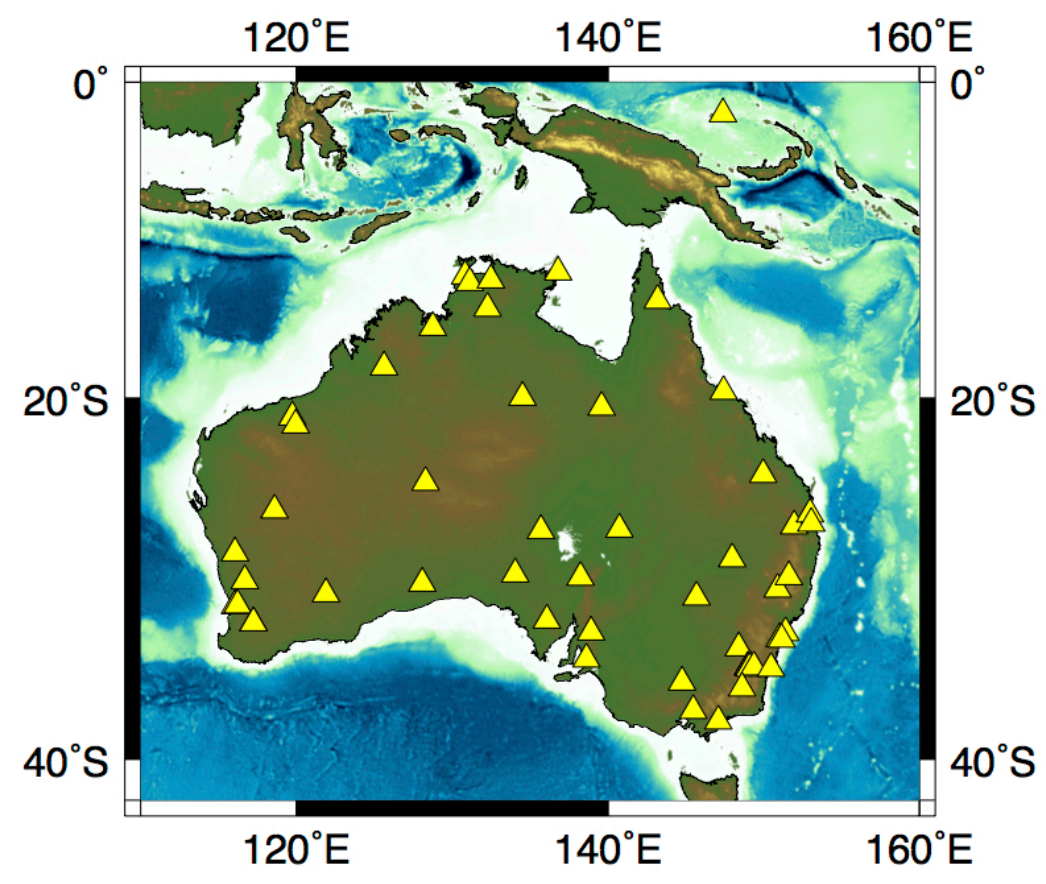

440

441 Figure S1: Station distribution of the Australian seismic network. Yellow triangles indicate the 442 stations used in the high frequency back-projection analysis. 


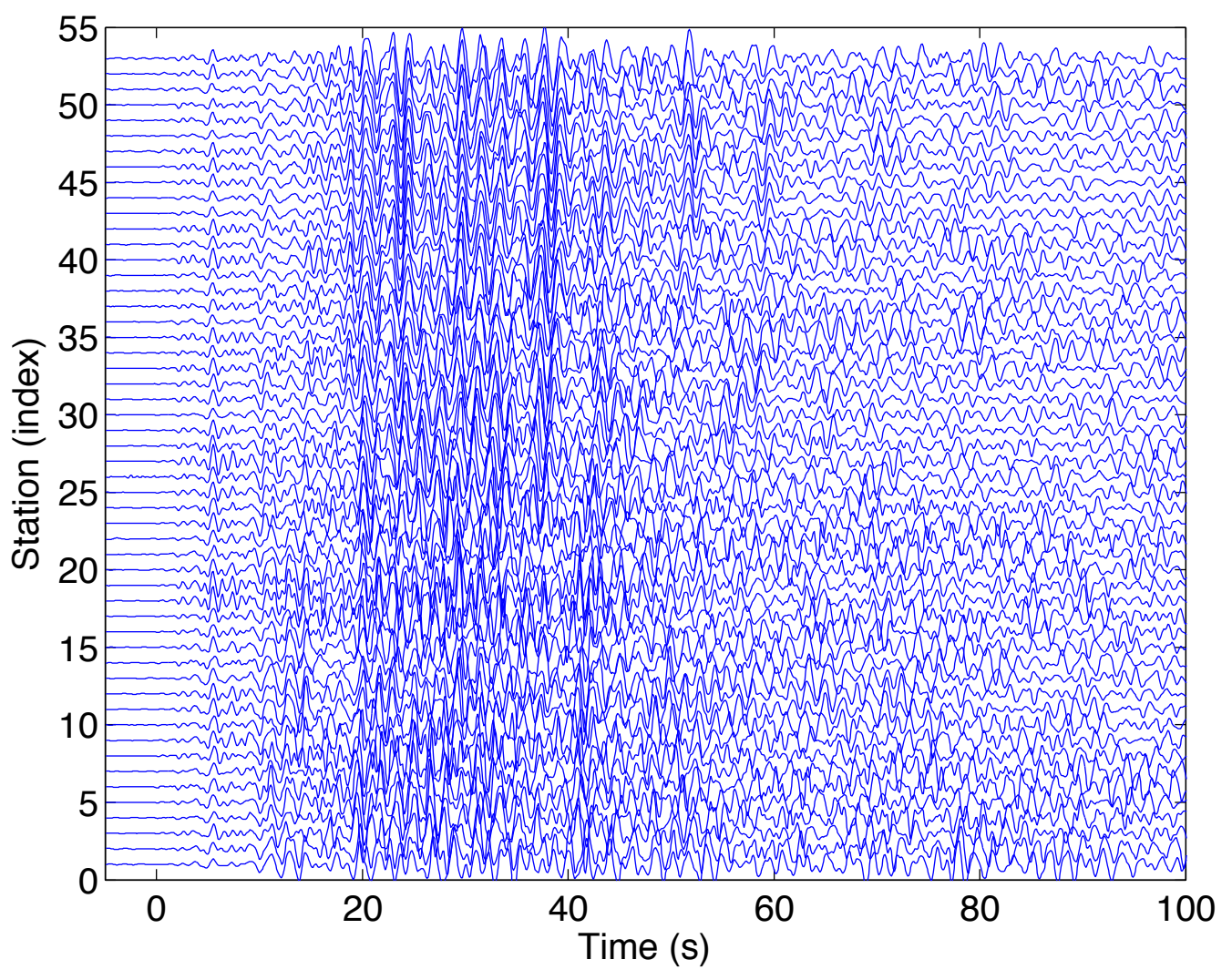

443

444 Figure S2: Seismograms $(0.5-2 \mathrm{~Hz})$ of the Gorkha earthquake recorded by the Australian 445 seismic network. The direct P-wave arrival is aligned at time zero. The station index is ordered 446 by epicentral distance. 
P19: azimuth
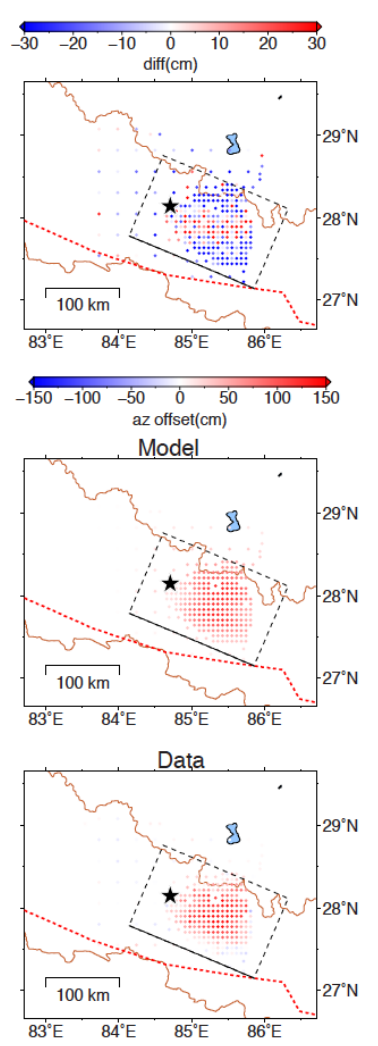

P19: range
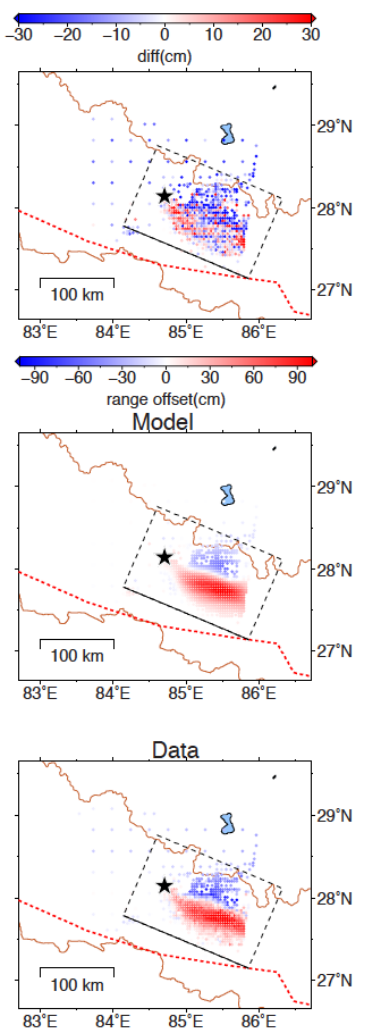

P85: azimuth
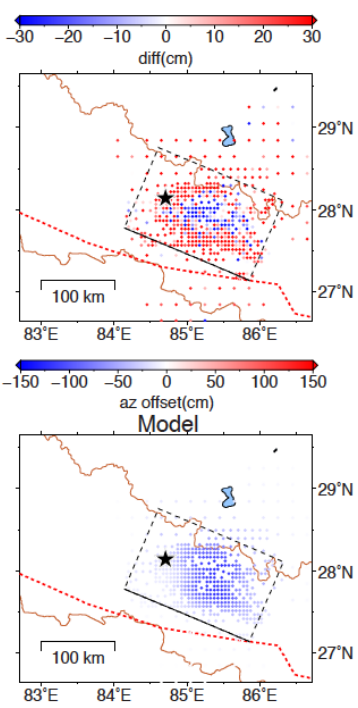

Data

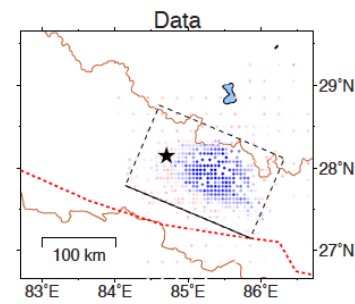

P85: range
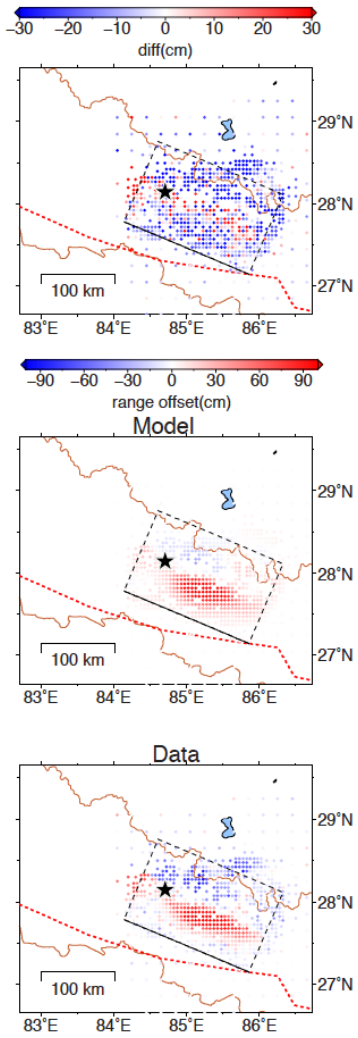

449 Figure S3: Comparison between the predicted and observed surface displacements derived from cross-correlation of descending (P19) and ascending (P85) images. 

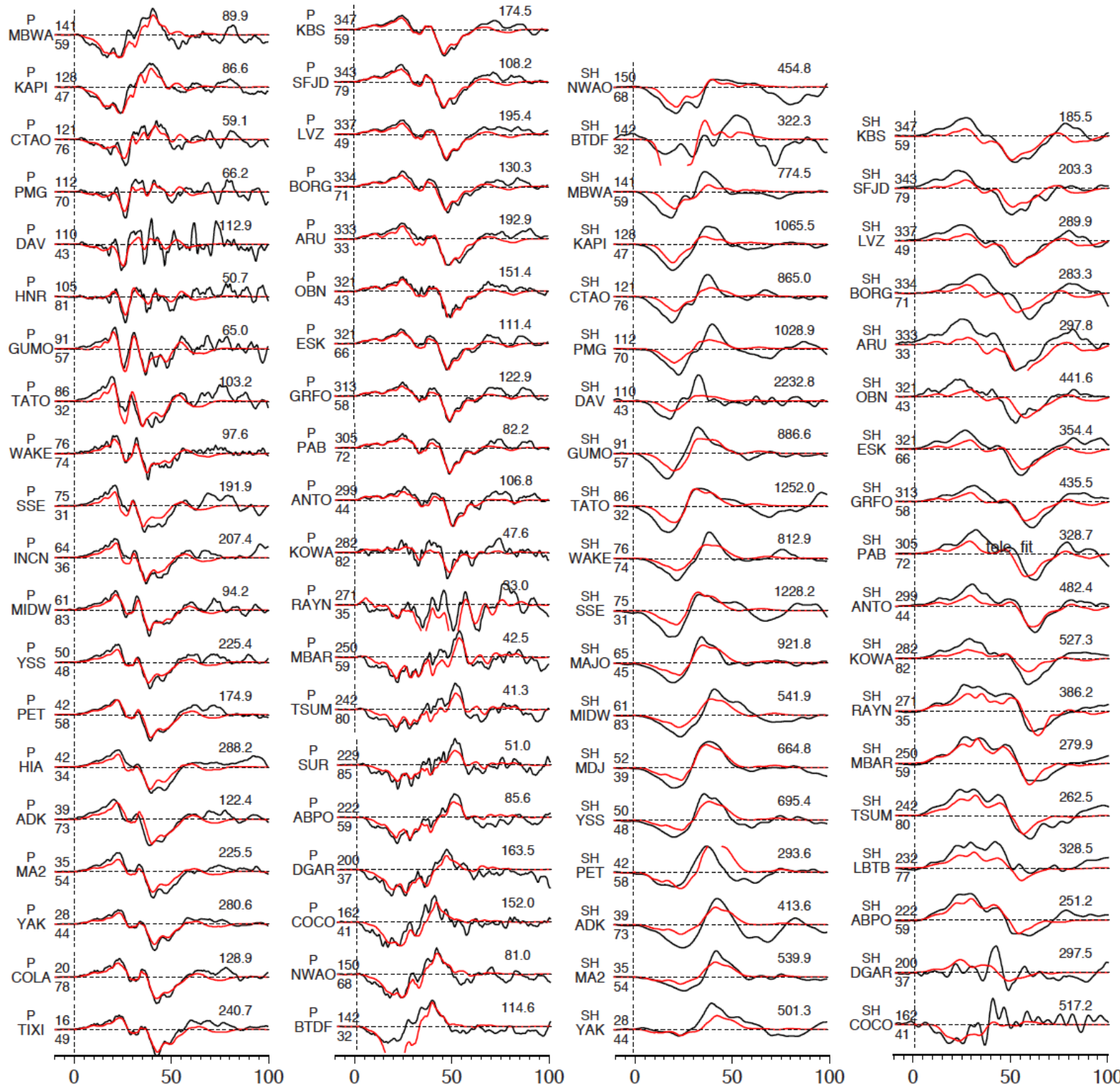

Figure S4 : Comparison between measured (black) and synthetic (red) teleseismic waveforms on the selected stations with P-waves shown on the left and $\mathrm{SH}$-waves on the right (time in seconds). Stations names are shown on the left of each waveform comparison along with azimuth (upper) and epicenter distance (lower) in degree. Stations are arranged such that the azimuth increases from bottom to the top. Note that the SH-waves are much broader in the direction away from the rupture than that towards the rupture, as indicated by the red arrows. 


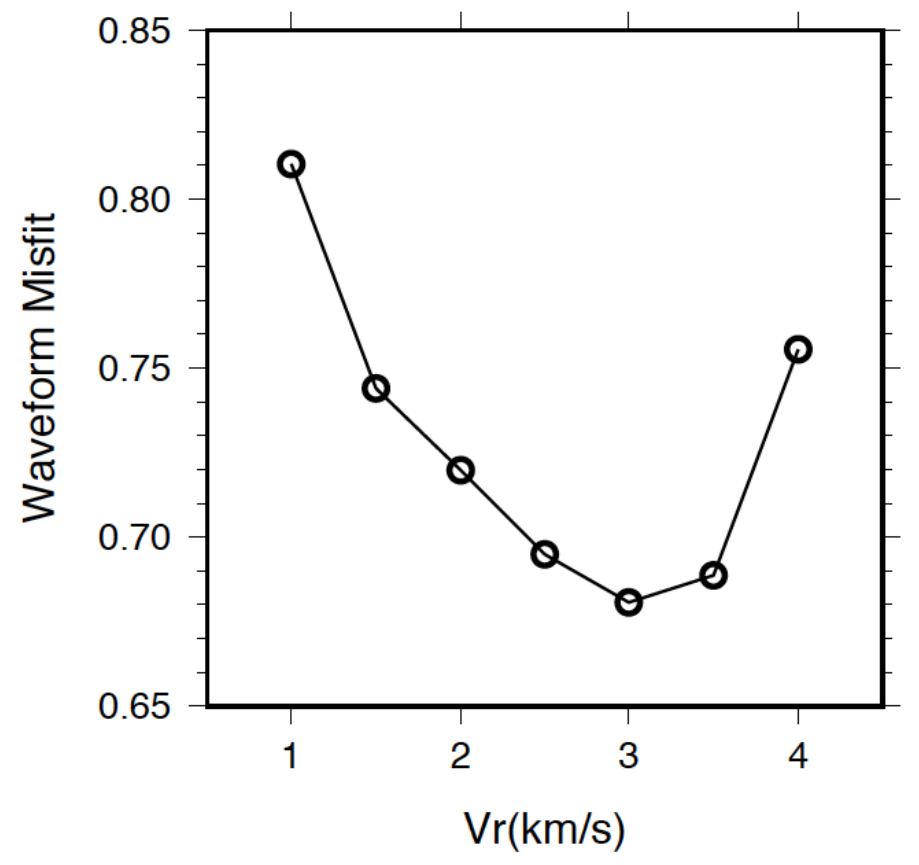

459 Figure S5: Misfit between observed and synthetic waveforms for models with imposed constant 460 rupture velocity.

461 

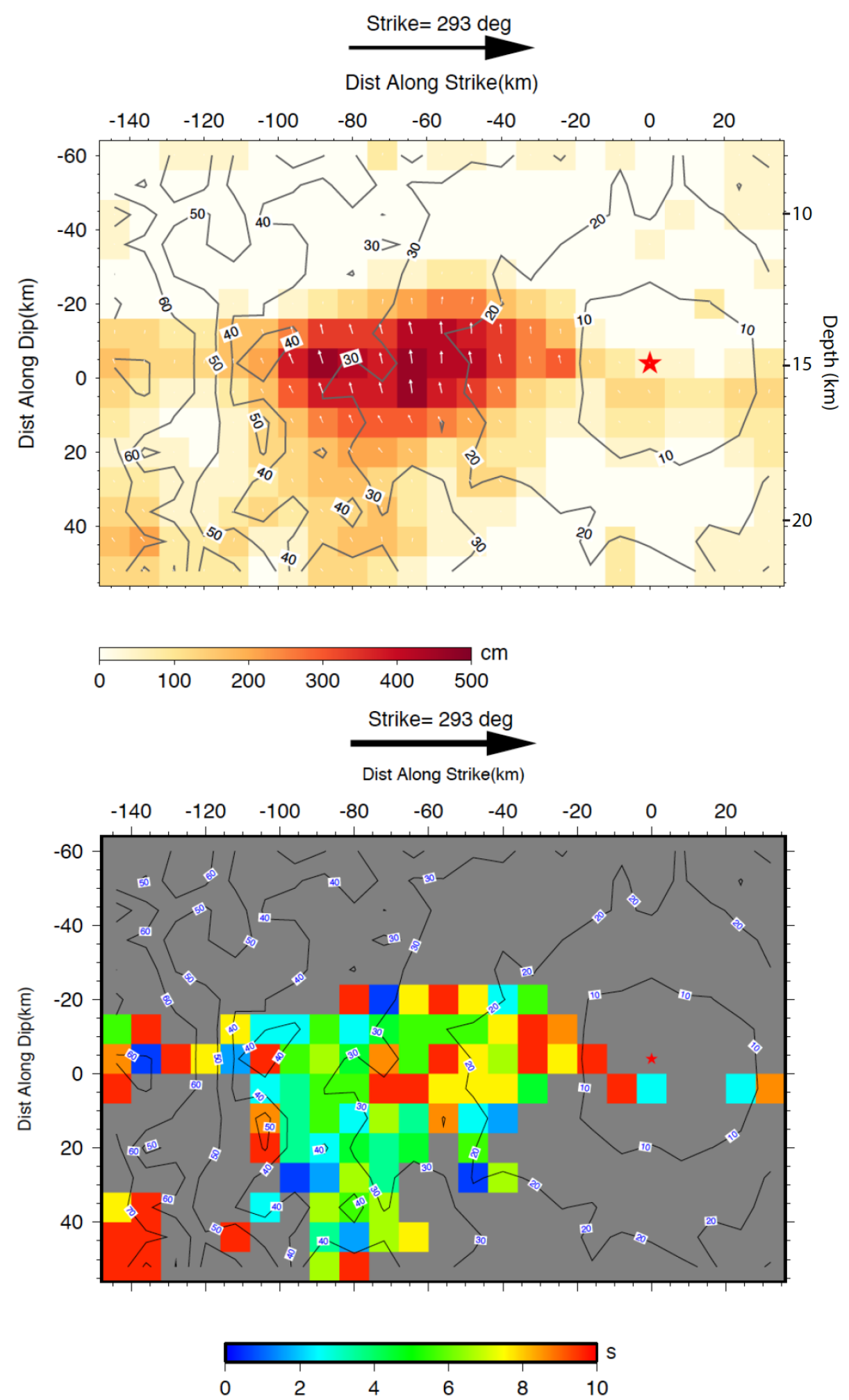

Figure S6: Top: Slip distribution in depth view, arrows indicate the rake angle and the slip amplitude is color coded. Rupture times are indicated by the contours. Bottom: Rise time distribution in depth view, only shows the slip patches with slip amplitude larger than $1 \mathrm{~m}$. 